\title{
Maurizio Onza \\ La mediación conciliatoria de los conflictos civiles y comerciales en Italia: un análisis jurídico y empírico*
}

Universidad de Brescia, Italia maurizio.onza@unibs.it Recibido: 02.08.18 Aceptado: 28.11 .18

\section{The conciliatory mediation in civil and commercial matters in Italy: a legal and empirical analysis}

\begin{abstract}
Resumen: El trabajo trata sobre la mediación conciliatoria de los conflictos civiles y comerciales en Italia, concentrándose en su integración en el sistema de las soluciones no jurisdiccionales de los conflictos. En esta vision, es necesario profundizar en el análisis sea de un punto de vista teórico sea de un punto de vista operativo, estudiando los datos empíricos.
\end{abstract}

Palabras clave: Mediación; mediación conciliatoria; análisis jurídico y empírico.Abstract: This work deals with the conciliatory mediation in civil and commercial matters in Italy, with respect to the relevant integration in the system provided for the extrajudicial resolutions of the conflicts. In this scenario, the analysis will focus on the theoretical point of view as well as on the practical one, also processing empirical data too.

Keywords: Mediation; conciliatory mediation; legal and empirical analysis.
La "mediación conciliatoria de los conflictos civiles y comerciales" es un procedimiento introducido en Italia con el decreto legislativo 28 de 2010, en aplicación de la ley delegativa $n^{\circ} 69$ de 2009 que contiene los principios [y] criterios directivos ${ }^{1}$ fijados por el Parlamento en los cuales el delegado del ejercicio de la función legislativa (el Gobierno), en la ejecución de la delegación, se ha tenido que ajustar.

La "mediación conciliatoria" ha sido evidentemente introducida para reducir la carga de trabajo de las autoridades jurisdiccionales, en función, por lo tanto, deflacionaria.

Analizar la "mediación conciliatoria" en Italia es una tarea particularmente compleja que requiere la elección de una perspectiva de investigación; lo cual implica el riesgo de parcialidad y la certeza de un inacabado análisis.

Con esta advertencia, que también sirve como el comienzo de la premisa, se han seleccionado aspectos que se consideraron más interesantes para el jurista y, en particular, para el jurista que observa otro ordenamiento.

Aspectos sobre los que intentaré detenerme mirando el contexto en el cual la "mediación conciliatoria" se inserta y las respuestas que su disciplina ofrece: desde un punto de vista jurídico, primero, luego dedicando alguna broma sobre su operatividad concreta.

\footnotetext{
* Ponencia realizada en el Seminario Internacional "Mediación de asuntos civiles y comerciales. Una visión comparada para su regulación en Chile", celebrada en la Universidad de los Andes, Santiago de Chile, 14 de mayo de 2018. La traducción al español de los textos citados es del autor (Nota de la ed.).

${ }^{1}$ Art. 76 Cost.
} 


\section{La "mediación conciliatoria" como técnica de solución de conflictos alternativa al procedimiento jurisdiccional: la "tensión" con el derecho a un "procedimiento jurisdiccional"}

Intuitivamente la "mediación conciliatoria" se sitúa, en el sistema, como una técnica de solución de conflictos entre pretensiones jurídicamente relevantes (por ejemplo, litigios) como alternativa a los procedimientos jurisdiccionales ${ }^{2}$, mediante la "conciliación" llegando a un "acuerdo", que se avala en la intervención de un tercero llamado "mediador"4.

Una característica que debe apreciarse no tanto $-\mathrm{y}$ no solo- en razón del momento temporal en el cual la técnica es aplicada ("antes" o "en el curso" del procedimiento jurisdiccional) $)^{5}$, sino, sobre todo, considerando el valor jurídico de la "solución" del conflicto objeto de la "conciliación".

Esta "solución" del conflicto, a buena vista, no está limitada a "procedimientos jurisdiccionales", sino que se verifica en "procesos verbales"6 que contienen la "solución conciliada", a los cuales el ordenamiento les reconoce, bajo ciertas condiciones, algunos efectos jurídicos que aseguran la estabilidad y la ejecución de la "solución": efectos que, de no producirse, la técnica alternativa sería inutiliter data [se le conceda], lo que la condena al seguro fracaso.
Así es que, resuelto el conflicto, es necesario cumplir las pretensiones "conciliadas", asignando ahora a aquella "solución", declarada en un "procedimiento no jurisdiccional", eficacia ejecutiva. Por lo tanto, se otorga a la "solución" título para la apertura del procedimiento ejecutivo ${ }^{7}$, permitiendo satisfacer la pretensión sin la "colaboración" de quien es sometido a aquella pretensión.

Parece evidente, entonces, que resolver un conflicto entre pretensiones jurídicamente relevantes y atribuir a esta "solución" eficacia ejecutiva, sin que tal "solución" sea apreciable como "procedimiento jurisdiccional”, entra en tensión con el derecho a la tutela jurisdiccional.

Es esto un "principio supremo del ordenamiento constitucional, directamente conectado con el principio de democracia que debe asegurar a todos y siempre, por cualquier controversia, un juez y un juicio"». Una decisión, por lo tanto, que aplica la "ley",

\footnotetext{
${ }^{2}$ Aunque la mediación conciliatoria puede actuar como una técnica alternativa, a su vez, a otra técnica alternativa a los procedimientos judiciales, como es el arbitraje: este es el caso de la "mediación" o "conciliación" prevista en una cláusula de "contrato", un "estatuto" o de una "escritura de constitución" de una entidad (Art. 5, quinto párrafo, D.Lgs. n²8/2010).

${ }^{3}$ La palabra "conciliación" significa "reconciliar, reconciliar y lograr"; y conciliar significa "ponerse de acuerdo" independientemente de la intervención de un tercero (De Mauro, 2000).

${ }^{4}$ Mediador significa "quien realiza el trabajo de mediación o interviene entre dos o más partes para facilitar la obtención de un acuerdo" (De Mauro, 2000).

${ }^{5}$ Como es el caso de la "mediación conciliatoria" que puede tener lugar tanto antes del proceso judicial (en algunos como condición para poder proceder) como durante el proceso, como se verá en el apartado 1.1 de esta investigación.

${ }^{6}$ Así, en las actas hay mucha discusión en la "mediación conciliatoria" (Art. 11, párrafos primer, tercer y cuarto, D.Lgs. n 28/2010) así como, ejemplarmente, en el intento obligatorio de conciliación en procedimientos judiciales ordinarios (Art. 185, 3er párrafo, c.p.c.); en la conciliación de conflictos laborales (art. 411 del Código Civil italiano - llamado c.c. - y 420 párrafo tercero, c.c.), este último también aplicable a las controversias relativas al arrendamiento, préstamo y alquiler); en asesoramiento técnico preventivo (artículo 696 bis c.c.). Y el "proceso verbal de conciliación", llevado a cabo ante un juez, está dedicado al Art. 88 de la disp. att. y trans. Código de Procedimiento Civil (llamado c.p.c.)

${ }^{7}$ En uno con la preferencia en el orden de satisfacción de los acreedores atribuido por la hipoteca judicial (previsto de manera general, para las sentencias y para las comisiones de elogio, cuando se hizo exigible: arts. 2818-2820 c.c.).

8 Tribunal Constitucional $n^{\circ} 18 / 1982$.

9 Por esta razón, incluso cuando la "medida jurisdiccional" se traduce "según la equidad" - hipótesis admisible para disputas "menores" (menos de 1.100 euros) - el juez debe "aplicar los principios que informan al sujeto" (Art. 113, primer párrafo, c.p.c., según lo interpretado por el Tribunal Constitucional con la pronunciación n²06/2004).
} 


\section{La mediación conciliatoria de los conflictos civiles y comerciales en Italia}

a la cual todo "juez" está vinculado ${ }^{10}$ y cuyo respeto debe ser racionalmente verificable a través de la "motivación" de la decisión ${ }^{11}$.

Principio, a su vez, que tiene un valor de derecho fundamental en la Unión Europea, que le atribuye a toda persona el derecho a un recurso efectivo, ante un juez independiente e imparcial, y consecuentemente, preestablecido por ley, llamado a examinar la causa introducida de manera "justa, publica" y dentro de un término razonable, asegurando a las partes involucradas, inclusive privados de medios (económicos) suficientes ${ }^{12}$ (llamado gratuito patrocinio), la "asistencia" y la "representación" de un profesional ${ }^{13}$.

Un principio tan relevante, entonces, como para ponerle límites incluso al arbitraje llamado ritual, técnica alternativa históricamente más cercana a la "jurisdicción", en los sentidos mencionados y atenida en modo más cercano al procedimiento jurisdiccional. Límites entre los cuales señalaría: (1) la exclusión de la legitimidad de un árbitro ritual obligatorio ${ }^{14}$; (2) la necesidad de una disposición textual para asignar a la "solución" del conflicto (el llamado laudo), los "efectos de la sentencia pronunciada de la autoridad judicial"15 y (3) la solicitud de intervención de la autoridad jurisdiccional ${ }^{16}$ para asignar eficacia ejecutiva al laudo previo una evaluación de su regularidad formal ${ }^{17}$.

1.1. La consecuente disciplina de la "mediación conciliatoria": las condiciones, los costos, los tiempos y la eficacia ejecutiva

Esta tensión, entre técnica alternativa de solución de conflictos entre pretensiones jurídicamente relevantes y el derecho de obtener un pronunciamiento jurisdiccional, ha provocado - no por casualidad- en la disciplina de la mediación conciliativa una declaración de inconstitucionalidad ${ }^{18}$ que nos ha impuesto una modificación, que data del $2013^{19}$. En la perspectiva de esta tensión, la disciplina de la "mediación conciliatoria" hoy vigente se traduce en algunas reglas que podrían ser así resumidas:

El experimento de la "mediación conciliatoria" es una (mera) condición de procedencia ${ }^{20}$ del proceso de origen jurisdiccional, que no puede en caso alguno restringir el acceso a la justicia ${ }^{21}$ y que conlleva una carga por asumir, que en algunos casos, específicamente indicados ${ }^{22}$, es anterior al inicio del procedimiento jurisdiccional y en otros durante el curso del procedimiento jurisdiccional, si el intento de "mediación conciliatoria" es propuesto por el juez ${ }^{23}$. De ello se deduce que la no realización de la "mediación de la conciliación", antes de la iniciación de los procedimientos judiciales o en el curso de la misma,

\footnotetext{
${ }^{10}$ Art. 102, segundo párrafo, Tribunal Constitucional.

${ }_{11}$ Art. 111, sexto párrafo, Tribunal Constitucional.

${ }^{12}$ Confrontar, también el Art. 24, párrafo tercero, Tribunal Constitucional.

${ }^{13}$ Art. 47 Carta de los Derechos Fundamentales de la Unión Europea (adoptada el 12 de diciembre de 2007), documento que tiene la misma significación jurídica que los "Tratados de la Unión Europea" de conformidad con el art. 6, § 1, del Tratado de la Unión Europea. Del mismo modo art. 6, § 1, Convenio para la Protección de los Derechos Humanos y las Libertades Fundamentales de 4 de noviembre de 1950, "principio general" en el derecho de la Unión Europea según el art. 6, párrafo 3, Tratado de la Unión Europea.

${ }^{14}$ Entre los primeros, Tribunal de la Constitución n 127/1977.

${ }^{15}$ Art. 824 bis c.p.c.

${ }^{16}$ En detalle, es el Tribunal territorialmente competente para pronunciar el "decreto" de "ejecución"; para el laudo extranjero, la competencia está enraizada en el Tribunal de apelación de acuerdo con los criterios descritos en el arte 839 c.p.c.

17 Art. 825, primeros párrafos, c.p.c.

18 Tribunal de la Constitución n²72/2012, intervino, esencialmente, en el primer párrafo del art. 5 D.Lgs. n²8/2010.

${ }^{19}$ D.I. n 69/2013 que también introdujo del art. 5 D.Lgs. n²8/2010 el párrafo 1-bis.

${ }^{20}$ Art. 5, párrafo 1-bis, D.Lgs. $n^{\circ} 28 / 2010$.

${ }^{21}$ Art. 60, tercer párrafo, b), L. n 69/2009.

${ }^{22}$ Art. 5, párrafo 1-bis, D.Lgs. $n^{\circ} 28 / 2010$.

${ }^{23}$ Art. 5, párrafo 2, D.Lgs. $n^{\circ}$ 28/2010. Cuando "la naturaleza de la causa, el estado de la educación y el comportamiento de las partes hace particularmente adecuado el recurso a soluciones amistosas del mismo, también teniendo en cuenta el contenido de las propuestas conciliatorias formuladas durante el juicio": Tribunal de Turín, n 4613/2017.
} 
obliga ${ }^{24}$ al Tribunal ${ }^{25}$ a pronunciar una declaración de improcesabilidad, que no excluye una nueva iniciación del procedimiento judicial. Por lo tanto, el juez no decide sobre el mérito del conflicto. En definitiva, la no aceptación de las cargas de inicio de la "mediación conciliatoria" no impide la re-proposición del requerimiento jurisdiccional; lo que genera, como consecuencia, la necesidad de tener que introducir incentivos para la aceptación de las cargas o desincentivos para no evadirla. La parte sobre la cual recae la carga, intuitivamente, coincide con el "actor" del eventual procedimiento jurisdiccional, siendo el sujeto que tiene interés en la introducción del procedimiento mismo, el cual será ahora condenado a las costas del litigio en caso de un pronunciamiento de improcedencia ${ }^{26}$. Estos incentivos y desincentivos son funcionales respecto a las condiciones de procedencia que, en cuanto a la "suspensión temporal" de la obtención de un "procedimiento jurisdiccional", es aplicable solo respecto a conflictos de seleccionadas materias ${ }^{27}$, no susceptibles, por lo tanto, de interpretaciones extensivas o analógicas ${ }^{28}$.

La realización de una "mediación conciliatoria" no interfiere con la posibilidad de obtener "medidas urgentes y cautelares", medidas que resuelven un conflicto cuya "solución tardía" podría socavar la utilidad de la teoría del conflicto ${ }^{29}$, caracterizada por el llamado periculum en residencia, y luego se resolvió con una llamada "medida jurisdiccional" y un "conocimiento incompleto" basado en la apariencia de los méritos del reclamo (llamada fumus boni iuris).

El costo de la "mediación conciliatoria", como condición de procedencia, debe ser contenido y previsible. En sintonía con esto, el D.Lgs. n 28/2010 prevé la indicación preventiva de mínimos y máximos de gastos, establece reducciones obligatorias y, para quien demuestre no tener los "medios" económicos suficientes, la exención total (llamado gratuito patrocinio) $)^{30}$. Al respecto, es oportuno evidenciar que los costos "contenidos" se refieren a las costas de la "mediación conciliatoria" y no de la asistencia de los abogados a las partes en conflicto, durante la mediación misma: asistencia convertida en obligatoria ${ }^{31}$. Se genera así una incompatibilidad parcial entre la "mediación conciliatoria" y la normativa de derivación europea, que en conflictos relativos a los consumidores legitima a estos a iniciar "conciliaciones" (comprendida la "mediación conciliatoria") sin la asistencia de abogados ${ }^{32}$ (por tal modo sin pagarnos el "costo"): en sintonía, ante estas hipótesis, el D.Lgs. $n^{\circ}$ 28/2010 ha sido inaplicado por estar en contraste con el derecho comunitario ${ }^{33}$.

La "suspensión" del derecho a acceder a un pronunciamiento jurisdiccional, como consecuencia de la apertura de la "mediación conciliatoria", está limitada en el tiempo ${ }^{34}$ y existen índices y modalidades que permiten

\footnotetext{
${ }^{24}$ En la interpretación preferible. De hecho, en algunos casos de "mediación conciliatoria" solicitada durante el proceso judicial, el juez, en ausencia de una pronta activación, no procedió con el fallo de impropiedad: detalles en Ferraris (2016, p. 631, nt. 3) la voz Mediación civil y comercial.

${ }^{25}$ Establecer un plazo corto (15 días) para la presentación de la aplicación. El término que la jurisprudencia tiende a no considerar perentorio dada la connotación "conciliatoria" de "mediación": v. Corte de la aplicación Milán, 25 de mayo de 2017. Sigue la necesidad de evaluar, caso por caso, las posibles consecuencias de no haberlo presentado oportunamente (v. Tribunal de Vasto, Sección del Trabajo, 27 de septiembre de 2017, sobre el mandato no perentorio, véase también Trib. Bolonia, $n^{\circ}$ 21109/2017). El hecho de que sea una condición procesal implica, además, que "el aplazamiento del juicio debido a la falta del proceso de mediación no socava las preclusiones procesales que, a mediano plazo, han madurado": Cass. n 9557/2017.

${ }^{26}$ Corte de Roma, $n^{\circ} 23237 / 2017$.

${ }^{27}$ Art. 5, párrafo 1-bis, D.Lgs. n² 28/2010.

${ }^{28}$ Corte de Bologna 1 de diciembre de 2011.

${ }^{29}$ Art. 5, tercer párrafo, D.Lgs. n 28/2010.

${ }^{30}$ Art. 17, párrafo cuarto e 5-bis, D.Lgs. n²8/2010. Confróntese Corte de Trieste, n 6797/2017.

${ }^{31}$ Art. 8, primer párrafo, D.Lgs. $n^{\circ}$ 28/2010 enmendado por el D.L. $n^{\circ}$ 69/2013. Asistencia que evidentemente no puede considerarse equivalente y si la asistencia como representación ante un tribunal (denominado jus postulandl): v. Cass. n 13886/2016 y el Tribunal de la Ley de Pavia, 14 de septiembre de 2015.

32 Tribunal de Justicia de la UE n 75/2017, en relación con la Directiva 2013/11/UE.

${ }^{33}$ Corte de Verona, 28 de septiembre de 2017.

${ }^{34}$ No pudiendo durar más de "tres meses", plazo no sujeto a suspensión laboral: art. 6, primer y segundo párrafo, D.Lgs. $n^{\circ} 28 / 2010$. Si la relación no es "congelar" el derecho a una "decisión judicial", es claro que este término no constituye un "límite de tiempo para la formación del acuerdo", operando "exclusivamente para la capacidad de acción de las aplicaciones judiciales": Corte de Roma, 22 de octubre de 2014.
} 
mantener implícitamente satisfecha la condición de procedencia, al tiempo que impiden revelarnos su ausencia. $\mathrm{Y}$ así, siempre que el primer encuentro frente al mediador concluya sin acuerdo o "conciliación"35, la condición de procedencia se reputa satisfecha; mientras que la falta de cumplimiento de esta condición de procedencia debe ser revelada por el demandado o por el juez, no antes de la primera audiencia posterior al inicio del procedimiento jurisdiccional o debe considerarse - ante la propuesta del juez- durante el curso del procedimiento jurisdiccional ${ }^{36}$.

La eficacia ejecutiva ${ }^{37}$ de la "solución conciliada" es atribuida - respetados ciertos requisitos de forma ${ }^{38}-$ siempre que todas las partes hayan sido asistidas por un abogado; en defecto ${ }^{39}$, aquella eficacia requiere de una disposición de la autoridad jurisdiccional ${ }^{40}$, de homologación de la solución previo examen de la regularidad formal y del respeto a las normas imperativas de orden público ${ }^{41}$. Esto permite evidenciar un perfil fundamental: en la "mediación conciliativa", la solución del conflicto parece susceptible de un vínculo débil en orden al respeto de la aplicación de las reglas de derecho ${ }^{42}$, incluida (si se considerase, como me parece que se debe, una regla no "de derecho") la equidad. En la disciplina de la "mediación conciliatoria", de hecho, no existe ninguna disposición textual que imponga una "solución conciliada" que aplique al conflicto concreto" reglas "de derecho": a buena vista, la verificación del respeto de las normas imperativas y de orden público está prevista, como recién hemos visto, solo en el caso (residual) de ausencia de asistencia de abogados para todas las partes. Y así, una "solución conciliada", que resuelva el conflicto concreto aplicando reglas de derecho, tampoco garantiza el deber del mediador de formular propuestas de conciliación que respeten los límites del orden público y de las normas imperativas ${ }^{43}$; propuestas que serán sometidas a las partes solo si todas lo solicitan ${ }^{44}$ (la facultad del mediador para hacer propuestas emana del art. 14, segundo párrafo, let. C), D.Lgs. n²8/2010. Tal facultad se convierte en un deber si todas las partes lo solicitan [Arte 11, párrafo 1, D.Lgs. n²8/2010]). Orden público y normas imperativas son, de hecho, un límite externo, por así decirlo, al reconocimiento de los efectos jurídicos (ejecutivos) de los actos atribuibles a la autonomía privada (es decir, el acuerdo en el que se fundamenta la "solución conciliada"). Hay que añadir que la propuesta de conciliación del mediador no siempre es necesaria, como ocurre en el caso del "acuerdo amistoso", en el que las partes concilian independientemente de la propuesta.

Dos corolarios. El primero: la aplicación de reglas de derecho a la solución del conflicto concreto, de un lado, se deja a la voluntad de las partes, del mediador y de los abogados que asisten a las partes. Así es que una eventual queja de las partes, por la no aplicación

\footnotetext{
${ }^{35}$ Art. 5, párrafo 2-bis, D.Lgs. n²8/2010.

${ }^{36}$ Art. 5, párrafo 1-bis e segundo párrafo, D.Lgs. n 28/2010.

${ }^{37}$ Como un "título ejecutivo para la expropiación forzosa, la ejecución para la entrega y liberación, la ejecución de las obligaciones de hacer y de no hacer, y para el registro de una hipoteca legal”, Art. 12, primer párrafo, D.Lgs. $n^{\circ}$ 28/2010; hipótesis, la de la hipoteca judicial, de tipo "especial" con respecto al Art. 2818 c.c. con la consecuencia de que "no hay posibilidad de una sindicación sobre el contenido del acto" (Tribunal Ascoli Piceno, 11 de octubre de 2017, sobre el problema, en doctrina, ver Ceolin (2018). La eficacia ejecutiva también puede fortalecerse estableciendo "el pago de una suma de dinero por cada violación o el incumplimiento de las obligaciones establecidas [en la "reconciliación"] o por la demora en su cumplimiento": art. 11, tercer párrafo, D.Lgs. n²8/2010.

${ }^{38}$ Art. 11, tercer párrafo, y 12 D.Lgs. $n^{\circ}$ 28/2010.

${ }^{39}$ Esta es una hipótesis residual porque, como se mencionó anteriormente, la asistencia de un abogado es obligatoria desde la "primera reunión [y durante las] reuniones posteriores, hasta el final del procedimiento": Art. 8, primer párrafo, D.Lgs. n 28/2010.

${ }^{40}$ El Presidente de la Corte que pronuncia un decreto. El control sobre la regularidad formal insiste en: "1) la firma de los partidos y el mediador; 2) la propiedad declarada del suscriptor de su condición legítima como sujeto incluido en las funciones de un órgano de conciliación debidamente registrado en el Ministerio de Justicia; 3) el origen del informe de una organización registrada en el registro de conformidad con los arts. 3 y 4 d.m. $n^{\circ} 180$ de 2010; 4) la inclusión en el acta de los detalles de dicho registro en el registro; 5) la trazabilidad del acuerdo al campo de la mediación de conformidad con el art. 2 y esa es la membresía del acuerdo en asuntos civiles y comerciales", Corte de Módica, 9 de diciembre de 2011.

${ }^{41}$ Art. 12, primer párrafo, D.Lgs. ${ }^{\circ}$ 28/2010.

42 Probablemente más débil que el laudo donde el riesgo de apelación debe orientarse para una definición lo más cercana posible a la aplicación de las reglas "por ley" (ver Art. 829, tercer, cuarto y quinto párrafos, c.p.c.).

${ }^{43}$ Art. 14, segundo párrafo, c), D.Lgs. n 28/2010.

${ }^{44}$ Art. 14, segundo párrafo, c), D.Lgs. $n^{\circ}$ 28/2010.
} 
de las reglas "de derecho", podrá ser dirigida contra los abogados, siempre que concurran los elementos de la responsabilidad civil, a riesgo de lo cual el abogado está hoy obligado a inmunizarse a través del establecimiento de un seguro profesional ${ }^{45}$. Para el mediador, en la actualidad, no se ofrece ningún seguro profesional, aunque se requiere la adopción de códigos de conducta ${ }^{46}$ y códigos de ética ${ }^{47}$, también a nivel europeo.

El segundo: la aplicación de las reglas de la "ley" puede ser impugnada, me parece, solo con los medios (restringidos) de oposición a la ejecución y los actos ejecutivos ${ }^{48}$. Es un perfil (con sus corolarios) que no puede sorprender. La "mediación conciliatoria" evoca un acuerdo entre las partes involucradas en el conflicto, que estas reputan conveniente prescindiendo de las reglas "de derecho", acuerdo al cual el mediador no tiene más que permanecer ajeno. No puede emitir juicios o decisiones vinculantes ${ }^{49}$, sino que, como máximo, solo puede formular una "propuesta" de acuerdo. No es un "lugar" de aplicación del derecho, sino de elección, concordada, de la "conveniencia" recíproca consagrada en el acuerdo; si se quiere, las partes involucradas eligen, aceptan y reconocen un grado de "justicia". Justicia, por lo tanto, intermediada por el mediador, que ha agilizado el acuerdo, pero que permanece ajeno.

Justamente, la búsqueda de la conveniencia recíproca, por lo tanto, legitima un complejo de incentivos a, y desincentivos a no, concluir el acuerdo. De esto se tratará más adelante. Perfil, creo, que es capaz de explicar la referencia en I. delegación ${ }^{50}$ [Art. 6, tercer párrafo, letra d], D.Lgs. $n^{\circ}$ 28/2010] al modelo de solución extrajudicial en el campo del derecho de sociedades, la intermediación financiera y los asuntos bancarios y crediticios ${ }^{51}$; áreas de conflicto que, evidentemente, requieren un grado de flexibilidad en la solución no jurisdiccional o acordada del conflicto, teniendo en cuenta, más que el derecho, las necesidades concretas de las partes. Lo mismo puede decirse del ajuste de la "mediación conciliatoria" al texto ${ }^{52}$ de la Directiva 2008/52/CE, dedicada a la conciliación amistosa de los conflictos transfronterizos ${ }^{53}$, en la que la aplicación de las reglas de derecho a la solución de los conflictos aparece, por definición, complicada por la transnacionalidad de la disputa y, por lo tanto, por el posible conflicto de fuentes normativas.

Por otra parte, la actualidad se caracteriza por la velocidad con la cual nuevos conflictos entre pretensiones surgen adelante, especialmente en Italia, donde el constante retardo en el "plantear las reglas jurídicas" de parte de los titulares del poder legislativo, a menudo estancadas o incapaces de trazar reglas generales actuando solo "en emergencia" sobre este o aquel sector. Lo anterior se traduce frecuentemente en la "suplencia" del legislador, por parte del juez que debe proponer "soluciones" jurisdiccionales en ausencia de supuestos planteados en textos de rango legal ${ }^{54}$, lo que lleva a entonces "inventar" (Grossi, 2017, p. 831) la solución sobre la base de todas las circunstancias fácticas (que asumen un inédito relevo jurídico, para los ordenamientos modernos) y, además, los principios del ordenamiento (Lipari, 2018).

1.2. La consecuente disciplina de la "mediación conciliatoria": el procedimiento entre "mediación" y "conciliación"

Las anotaciones previas, todas reconducibles a la cualificación no jurisdiccional del acuerdo en el cual se sitúa la "solución conciliada", éxito de la "mediación conciliatoria", permiten también entender algunos otros pasos sobre los cuales es oportuno detenerse brevemente.

\footnotetext{
${ }^{45}$ De cuyos extremos el abogado debe informar al cliente y al Consejo de la asociación de abogados a la que pertenecen (Art. 12, 1 er y 3er párrafo, L. n²47/2012).

${ }^{46}$ Art. 4, § 1, Directiva 2008/52/CE.

${ }^{47}$ Art. 6, tercer párrafo, D.Lgs. n 28/2010.

${ }^{48}$ Arts. 615 ss. c.p.c.

${ }^{49}$ Art. 1, b), D.Lgs. $n^{\circ} 28 / 2010$

${ }^{50}$ V. Art. 60, tercer párrafo, c), L. n 69/2009.

${ }^{51}$ D.lgs. $n^{\circ} 5 / 2003$ y, difusamente, arts. 38 y siguientes.

${ }^{52}$ Eso se puede leer en el análisis "técnico-normativo" contenido en el informe ilustrativo del D.Lgs. n 28/2010.

${ }^{53}$ Directiva 2008/52/CE, Arts. 1, §§ 1 y 2.

54 Por lo tanto, hemos hablado de "crisis en este caso" (Irti, 2014). Y ahora Irti (2016).
} 
El mediador siendo tercero respecto a las partes involucradas, debe subscribir una declaración de imparcialidad, y le está vedado recibir compensaciones económicas directamente de las partes y, más en general, asumir derechos u obligaciones que aquella imparcialidad pudiera minar ${ }^{55}$. Ello impone, en primer lugar, la substracción de la selección del mediador a las partes involucradas ${ }^{56}$, individualmente consideradas, elección que queda entregada a un "organismo de mediación", elegido por las partes ${ }^{57}$, que designa, en modo imparcial pero no arbitrario ${ }^{58}$, al mediador, y que está sujeto a reglas de acreditación y de vigilancia de la autoridad gubernativa ${ }^{59}$, para garantizar la seriedad y eficiencia ${ }^{60}$, a través de la inscripción, y la permanencia de la inscripción, en un registro destinado a este propósito ${ }^{61}$.

La "mediación conciliativa" asume los caracteres de un "servicio de mediación"62 que, como otros servicios de "masa", es profesionalmente ofrecido al público por parte de los organismos antes señalados. Su oferta permite, en los límites de las fuentes primarias y secundarias, diferenciar el servicio prestado dentro de un régimen de competencia ${ }^{63}$, lo que legitima a los organismos de mediación para dotarse de diferentes reglamentos que son además revisados por la autoridad gubernamental para su registro, en cuanto verdaderos actos contenedores de la autonomía disciplinaria del procedimiento de mediación y de sus costos asociados ${ }^{64}$; regulaciones que serán evaluadas por la autoridad gubernamental para su inscripción en el registro ${ }^{65}$.

La cualificación no jurisdiccional de la solución al conflicto y la consecuente y natural ausencia del "rigor" de la aplicación de las normas de derecho (buscando la "solución" más conveniente), entonces, justifican la posibilidad de que los mediadores no sean "juristas", lo que no resta valor, tratándose de un "servicio profesional", por cuanto el mediador debe estar profesionalmente preparado para la tarea, preestableciéndose por lo tanto requisitos mínimos ${ }^{66}$ y obligaciones de formación de parte de los sujetos acreditados (los así llamados "entes formadores") ${ }^{67}$. Las competencias de cualquier mediador, sin embargo, no son irrelevantes, ya que orientan la designación en el caso específico68. Así, y debiendo "mediar para conciliar" un conflicto de pretensiones jurídicamente relevantes, es racional la previsión que involucra a los abogados como mediadores "de derecho", salvo obligaciones de formación (también continua) específica ${ }^{69}$, el mediador puede valerse de expertos inscritos en el registro de consultores, aunque solo de manera excepcional, ya que la nominación del experto aumenta los gastos del procedimiento ${ }^{70}$. Cuando el conflicto requiera específicas competencias técnicas, el organismo de mediación podrá nominar mediadores

${ }_{55}$ Art. 14, primer párrafo, D.Lgs. $n^{\circ}$ 28/2010.

56 Tener que admitir "la posibilidad de una indicación común del mediador por las partes, a los efectos de su posible nombramiento por parte del organismo": art. 7, quinto párrafo, c), d.m. 180/2010.

57 Art. 3, primer párrafo, D.Lgs. $n^{\circ} 28 / 2010$.

${ }_{58}$ Tener que cumplir con los procedimientos de nombramiento preconstituidos e insertarlos en el reglamento que garantizan no solo la imparcialidad sino también "la idoneidad para la finalización correcta y rápida de asignación" (Art. 3, segundo párrafo, D.Lgs. n 28/2010); luego también revelando las habilidades.

${ }^{59}$ Encomendado al Ministerio de Justicia y, para los asuntos de consumo, al Ministerio de desarrollo económico.

${ }^{60}$ Art. 16, primer párrafo, D.Lgs. n 28/2010.

${ }^{61}$ Art. 16, secundo, tercer y cuarto párrafos, D.Lgs. $n^{\circ}$ 28/2010. Sobre los requisitos para el registro, ver Art. 4 d.m. $n^{\circ} 180 / 2010$.

${ }^{62}$ Art. 4, § 1, Directiva 2008/52/CE.

${ }^{63}$ El número de organismos de mediación al 24 de marzo de 2014 era n 1015 (Cámara de Diputados-Expediente $\left.n^{\circ} 107\right)$.

${ }^{64}$ Art. 1, g), y art. 7 d.m. $n^{\circ} 180 / 2010$.

${ }^{65}$ Art. 16, tercer párrafo, D.Lgs. n²8/2010.

${ }^{66}$ En primer lugar, con respecto a la calificación: art. 4, tercer párrafo, a), d.m. 180/2010.

${ }^{67}$ Que garantizan "altos niveles de formación": art. 16, quinto párrafo, D.Lgs. n 28/2010 y Art. 18 d.m. n 180/2010.

${ }^{68}$ De hecho, en la regulación de los órganos de mediación, es necesario indicar "criterios obligatorios para la asignación de asuntos predeterminados de mediación respetando la competencia profesional específica del mediador designado, también deducida del tipo de título universitario poseído", art. 7, quinto párrafo, e), d.m. 180/2010.

${ }^{69}$ Art. 16, párrafo 4-bis, D.Lgs. n 28/2010: los mediadores de abogados deben estar "adecuadamente capacitados" también a través de "caminos de actualización". En el mismo sentido, se prevé un procedimiento simplificado para el registro en el registro de instituciones de mediación por los consejos de abogados (Art. 18 D.Lgs. $n^{\circ}$ 28/2010).

${ }^{70}$ Art. 8, cuarto párrafo, D.Lgs. $n^{\circ}$ 28/2010. 
auxiliares ${ }^{71}$. Ellos permiten hacer la solicitud de inicio del procedimiento sin mayores formalidades, con fórmulas de adhesión tendencialmente estandarizadas (en línea con el carácter de oferta de "masa" del "servicio de mediación"), en donde basta con identificar el organismo de mediación, las partes, el hecho y las razones (no necesariamente "de derecho") de la pretensión ${ }^{72}$ sobre la cual las partes discutirán con el mediador ${ }^{73}$. Se desprende que se trata de una "instancia" capaz de englobarse en formularios pre-compilados ${ }^{74}$.

Además, legitiman un procedimiento dividido en reuniones, la primera de las cuales se fija dentro de los treinta días posteriores a la solicitud ${ }^{75}$, sin formalidad ${ }^{76}$ (al igual que las escrituras relativas ${ }^{77}$ ) y sujeto a conformación, a través de la regulación del cuerpo de mediación dentro de los límites indicados en las fuentes legales primarias y secundarias. Entre estos límites, más lógicos que jurídicos, señalaría dos: toda mediación dirigida a un acuerdo requiere la posibilidad de que cada parte involucrada participe, dialogue y busque la solución más conveniente ${ }^{78}$. En este sentido, la prohibición de las reglamentaciones en cuanto a facilitar el acceso a la mediación exclusivamente a través de las modalidades telemáticas es ejemplar ${ }^{79}$. Toda mediación requiere la imparcialidad e independencia del mediador con respecto a las partes, no solo al comienzo ${ }^{80}$, sino también durante el curso del proceso ${ }^{81}$. Por lo tanto, ejemplarmente, son prohibidas las comunicaciones de las partes al mediador y este es obligado a informar a las partes y al organismo en caso sobreviniente de peligro de "parcialidad"82.

La circunstancia que la "solución conciliada" sea un acuerdo (no jurisdiccional) supone que las pretensiones jurídicamente relevantes en conflicto sean susceptibles de modificarse (y eventualmente de extinguirse) por las partes involucradas. Entonces, se debe tratar de pretensiones que atribuyan derechos disponibles ${ }^{83}$ a las partes. Esto justifica (1) La obligación de reserva ante terceros ${ }^{84}$ participantes del procedimiento ${ }^{85}$, para facilitar el alcance del acuerdo ${ }^{86}$; (2) la aplicación de las reglas sobre el secreto profesional, ante todo al mediador ${ }^{87}$; así como (3) la irrelevancia en los procedimientos jurisdiccionales de las informaciones y de las declaraciones rendidas en el procedimiento de mediación ${ }^{88}$.

\footnotetext{
${ }^{71}$ Art. 8, primer párrafo, D.Lgs. $n^{\circ}$ 28/2010.

${ }^{72}$ Cuando se requiere una "medida jurisdiccional", se hace referencia a las reglas "legales" (para la cita, Art. 163, tercer párrafo, $n^{\circ} 4$, c.p.c.) o las "razones para la solicitud" (Art. 125, primer párrafo, c.p.c.), que evoca, dada la referencia a la "aplicación" (y no a la "reclamación"), la necesidad de un argumento a modo de reglas "legales".

${ }^{73}$ Art. 4, segundo párrafo, D.Lgs. n²8/2010.

${ }^{74}$ En el tema, Marzocco (2012).

${ }^{75}$ Art. 8, primer párrafo, D.Lgs. $n^{\circ} 28 / 2010$.

${ }^{76}$ Art. 8, segundo párrafo, D.Lgs. n²8/2010.

77 Art. 3, cuarto párrafo, D.Lgs. $n^{\circ} 28 / 2010$.

${ }^{78}$ V. Corte de Pavía, 14 de octubre de 2015, según el cual "el procedimiento de mediación es un procedimiento confidencial, en gran medida oral y, en muchos sentidos, informal", cuyo "momento más importante" se constituye de la actividad del mediador "obligado a trabajar para que las partes lleguen a un acuerdo amistoso, sin ninguna otra especificación del contenido de la actividad del mediador, que se confirma esencialmente mediante el diálogo con las partes y los defensores".

${ }^{79}$ Art. 7, cuarto párrafo, d.m. n 28/2010. Medio, en línea, que si fomenta la participación entre partes físicamente distantes (y de hecho está expresamente previsto en el art. 3, cuarto párrafo, D.Lgs. n²8/2010), no se dice que sea accesible para todos.

${ }^{80}$ Art. 3, primer y segundo párrafos, D.Lgs. n²8/2010.

${ }^{81}$ Excepto "los realizados durante sesiones separadas": art. 7, séptimo párrafo, d.m. n 180/2010.

82 Art. 14, segundo párrafo, b), D.Lgs. $n^{\circ}$ 28/2010.

${ }^{83}$ Art. 2, primer párrafo, D.Lgs. $n^{\circ}$ 28/2010 y art. 60, tercer párrafo, a), I. n 69/2009.

${ }^{84}$ Es decir: participantes en el cuerpo mediador, mediador y, diría, mediadores auxiliares y consultores.

${ }^{85}$ Art. 9, primer párrafo, D.Lgs. n²8/2010.

${ }^{86}$ Con el consentimiento del declarante: art. 9, segundo párrafo, D.Lgs. $n^{\circ}$ 28/2010.

${ }^{87}$ Art. 10, primer párrafo, D.Lgs. n 28/2010 que recuerda el art. 200 Còdigo de procedimiento penal.

${ }^{88}$ En este caso, con la excepción del consentimiento del declarante: art. 10, primer párrafo, D.Lgs. n²8/2010. V. Corte de Treviso, 1 de marzo de 2016.
} 


\section{La "mediación conciliatoria" entre las técnicas de solución de conflictos alternativas al procedimiento jurisdiccional: el objeto del conflicto y los incentivos (y desincentivos)}

Las referencias al acuerdo y a los derechos disponibles, entonces, permiten incluir otros dos principios fundamentales de la "mediación conciliativa", referidos al conflicto potencialmente objeto de "acuerdo", y a los incentivos y desincentivos al inicio del procedimiento y a la conclusión del acuerdo.

Conviene analizarlos separadamente. Respecto al objeto susceptible de ser "conciliado", las partes pueden acordar sobre cualquier derecho disponible ${ }^{89}$, inherente a una controversia civil o comercial90.

Como fue evidenciado más arriba, en tales conflictos, la "mediación conciliativa" es condición de procedencia para obtener un "procedimiento jurisdiccional". Se trata de conflictos que tratan sobre materias que pertenecen a: relaciones destinadas a prolongarse en el tiempo o en las cuales se encuentran involucrados sujetos pertenecientes a la misma familia, grupo social o área territorial, para los cuales parecen preferibles soluciones extrajudiciales que favorezcan la continuación de la relación (copropiedad, arrendamiento, comodato, alquiler de compañía, derechos reales, divisiones, sucesiones, pactos de familia); relaciones particularmente conflictivas, con respecto a las cuales parece más fértil el terreno de la composición judicial (responsabilidad médica y difamación por medios de prensa); tipos contractuales que, además de sustentar relaciones duraderas entre las partes, sean relativos a una difusión de masa (contratos de seguros, bancarios y financieros ${ }^{91}$.

Dos son las observaciones que parecen pertinentes. La primera, respecto a la presencia de técnicas de solución de conflictos alternativas al procedimiento jurisdiccional que son sustitutivas a la "mediación conciliatoria", incluso sobre conflictos que versan sobre materias del todo asemejables a aquellas previstas para esta. Pienso, por ejemplo, en el resarcimiento del daño causado por la circulación de vehículos y embarcaciones ${ }^{92}$, como resultado típico de "relaciones conflictuales" frecuentes, normalmente sujetas a composición, como condición de procedencia a los (distintos) "procedimientos de negociación asistida por uno o más abogados”93.

La segunda, respecto a la presencia de técnicas de solución de conflictos alternativas al procedimiento jurisdiccional que puedan ser potencialmente ${ }^{94}$ concurrentes con la "mediación conciliatoria", son el Arbitrio Bancario Financiero (llamado ABF) y el Arbitrio para las Controversias financieras (llamado ACF), los cuales son textualmente tenidos (a su vez) como alternativos (y algo completamente opcional) a la "mediación conciliatoria"95. Concurrencia cuanto menos oportuna en razón de la alta especialización que tanto la materia

\footnotetext{
89 Estos no son, por ejemplo, los derechos del c.c. personal y "estado".

90 Art. 2, primer párrafo, D.Lgs. $n^{\circ} 28 / 2010$.

${ }_{91}$ Ver Informe explicativo el D.Lgs. n²8/2010, p. 5.

${ }^{92}$ Circulación sujeta a seguro de daños obligatorio.

${ }^{93}$ Arts. 2 y siguientes. D.L. n 142/2014, evidentemente caracterizado por negociaciones (sin mediadores) entre las partes asistidas por abogados.

${ }^{94}$ El tema del conflicto y la legitimidad al inicio de estas técnicas no son, entre los diferentes perfiles, siempre y totalmente coincidentes con los de la "mediación conciliatoria". Ragguagli, para el llamado ABF, en Lucchini Guastalla (2015); y para el llamado ACF, en Simone (2018), la conferencia Procedimiento de la Consob, en Informes Legales Co. n. so.b., 26 de febrero de 2018, n 16. También debe tenerse en cuenta que los dos árbitros también difieren en términos del valor legal de la "reconciliación", el incumplimiento al que esencialmente produce "efectos reputacionales" para la parte que incumple.

${ }^{95}$ Art. 5, párrafo 1-bis, D.Lgs. $n^{\circ}$ 28/2010 que se refiere tanto al llamado ABF (Art. 128-bis D.Lgs. 1.0 diciembre 1993, $n^{\circ} 385$ ) y al llamado ACF (establecido por el art. 32-ter D.Lgs. 24 febrero 1998, n 58, introducido por el D.Lgs. 3 agosto 2017, n 129).
} 
bancaria y financiera suponen, poco coherente con los mediadores (los cuales, como hemos visto, pueden ser limitados en sus competencias específicas sobre el tema) y totalmente coherente con los así llamados ABF y ACF, compuestos de profesionales altamente especializados.

Viceversa, se mantienen excluidos los conflictos relativos a algunas materias, cuya solución está destinada a procedimientos jurisdiccionales puestos a medida de intereses para los cuales una tentativa preventiva obligatoria de mediación ${ }^{96}$ parece inútil o contraproducente frente a la tutela jurisdiccional97, llevada en forma sumaria y que no requiere de un contradictorio previo, para asegurar celeridad en la satisfacción de los intereses mismos.

Pasando a los incentivos y desincentivos a la apertura del procedimiento, a la participación y a la conclusión de la "solución conciliada", se puede observar que estos pueden sustentarse (1) en incentivos y desincentivos económicos; y (2) en incentivos y desincentivos respecto a la decisión de la solución del conflicto en un procedimiento jurisdiccional.

Desde el punto de vista económico: al inicio del procedimiento son funcionales las ventajas fiscales, en la forma de exención de impuestos sobre documentos del procedimiento, así como de crédito de impuesto reconocido, sea sobre la medida como tal, o en el caso de fallido alcance de una "solución conciliada"98, en la conclusión de la "solución conciliada" es funcional un régimen especial de las costas procesales del procedimiento jurisdiccional, tenido a consecuencia de la fallida adhesión a la propuesta formulada por el mediador ${ }^{99}$. Derogando el régimen ordinario que sitúa las costas procesales en el vencedor ${ }^{100}$, sobre el vencido, aquellas inherentes a la "mediación conciliativa" son impuestas por el juez sobre el que ha rechazado la propuesta, siempre que la decisión jurisdiccional corresponda integralmente al contenido de la propuesta rechazada, con la condena de reembolsar las costas sostenidas por el vencido y la entrega al erario de una tasa llamada "de contribución unificada" (por ejemplo, la tasa necesaria para iniciar un procedimiento jurisdiccional civil) ${ }^{101}$. Además, el juez puede imponer al vencedor del proceso jurisdiccional las costas de la "mediación conciliativa" en caso de adherencia solo parcial entre el contenido de la propuesta (rechazada) y el procedimiento jurisdiccional, siempre que concurran graves y excepcionales razones y sea expuesta la motivación ${ }^{102}$. La participación en el procedimiento es un deber del juez para condenar a la parte que no ha participado sin motivo justificado al pago al tesoro por un monto igual a la llamada contribución unificada ${ }^{103}$. Respecto a los incentivos y desincentivos relativos a la decisión de las soluciones mediante un "procedimiento jurisdiccional", a fallida participación en el procedimiento de "mediación conciliatoria", sin justificado motivo, constituye "argumento de prueba" en el juicio.

\footnotetext{
96 Informe explicativo del D.Lgs. n 28/2010, p. 7. Son los indicados en el art. 5, cuarto párrafo del D.Lgs. n² 28/2010, es decir: "medidas cautelares, incluida la oposición, hasta la resolución sobre las solicitudes de concesión y suspensión de la ejecución provisional...; procedimientos para la validación de la licencia o desalojo, hasta el cambio del procedimiento...; procedimientos de asesoramiento técnico previo a los fines de la composición de la diferencia...; el proceso del poseedor, hasta que el fallo de la orden acepte o rechace la solicitud; Procedimientos de oposición o jurisdicción incidental relativos a la ejecución;... procedimientos en la cámara del consejo;... la acción civil ejercida en el juicio penal".

${ }^{97} \mathrm{La}$ acción de clase de los consumidores y la de las asociaciones de consumidores (Arts. 37, 140 y 140 bis D.Lgs. $\mathrm{n}^{\circ}$ 206/2005, el llamado Código del Consumidor): informe ilustrativo al D.Lgs. n²8/2010, p. 6. También art. 23, segundo párrafo, D.Lgs. n²8/2010 tambièn salva los procedimientos de conciliaciòn sectorial obligatorios, previstos para temas especificos, como el procedimento para disputas entre usuarios y operadores de comunicaciones electrónicas (Marzocco, 2012), especialmente las páginas 187 y siguientes.

${ }^{98}$ Art. 20 D.Lgs. $n^{\circ} 28 / 2010$.

${ }^{99}$ Reglas para ser notificadas por el mediador cuando se presente la propuesta de conciliación: art. 12, primer párrafo, D.Lgs. n²8/2010. 100 Art. 91, primer párrafo, c.p.c. Es una excepción sistemáticamente significativa que postula una "decisión judicial”, quedando así inaplicable, a menos que las partes lo decidan, en el caso de una "mediación conciliatoria" iniciada antes de un arbitraje en el que la decisión no es exquisitamente jurisdiccional pero solo bajo ciertas condiciones equiparadas por ley: art. 13, tercer párrafo, D.Lgs. $\mathrm{n}^{\circ}$ 28/2010.

101 Art. 13, primer párrafo, D.Lgs. $n^{\circ}$ 28/2010.

102 Art. 13, segundo párrafo, D.Lgs. n 28/2010.

${ }^{103}$ Siempre que se trate de una "mediación conciliatoria" requerida para el procesamiento de la solicitud: Art. 8, párrafo 4-bis, D.Lgs. n 28/2010.
} 


\section{La "mediación conciliatoria" y su concreto funcionamiento: alguna revelación empírica}

Quisiera cerrar esta exposición con algún dato empírico. Partiría por esto: en el 2016, los habitantes en Italia eran 60,6 millones, de los cuales 243.680 eran abogados. Un número de abogados por habitante entre los más altos de Europa; en el 2017, las causas civiles pendientes eran iguales a 3.628.936 $6^{104}$; siempre en el 2017, los asuntos pendientes, capaces de generar un derecho de indemnización por irrazonable duración del proceso ${ }^{105}$, violando los principios europeos de los cuales hemos hablado en el inicio, eran, en distintas etapas del juicio, iguales a 77.133, 127.244 y $407.017^{106}$; en Italia, la percepción de la justicia y de desconfianza es muy alta: el $52 \%$ de aquellos que han tenido una experiencia directa con la justicia civil ha declarado sentirse poco o nada satisfechos. De los mismos, el 68,6\% estima necesario, sobre todo, reducir la duración de los procedimientos; el $57,7 \%$, simplificar los aspectos burocráticos; y el 31\%, garantizar la puntualidad a las audiencias; entre los años 2012-2015, un millón y medio de personas ha decidido renunciar a iniciar una causa civil por el temor de cargar con costos demasiado elevados respecto a la ventaja conseguible $(30,8 \%)$, por la incertidumbre de los tiempos de desarrollo $(25,6 \%)$ o del resultado favorable $(15,5 \%)^{107}$.

Estos números y esta desconfianza, que desde hace años son sustancialmente los mismos, han orientado al legislador italiano a intervenir en el ordenamiento a través de distintas modalidades: (1) reduciendo las hipotesis de impugnación (tanto en apelación como en casación) $)^{108 ;}$ (2) introduciendo "sanciones" en la forma de resarcimiento del daño, cuando la accion jurisdiccional fue propuesta "sin la normal prudencia", admitiendo, por lo tanto, en todo caso, la condena al pago de una suma determinada en modo equitativo ${ }^{109}$; (3) imponiendo el deber de sintetizar los hechos, tanto por las partes como por el juez ${ }^{110}$; (4) requiriendo que la justificación de las medidas jurisdiccionales sea "concisa" y "sucinta"111.

Y, naturalmente, el legislador ha ampliado y potenciado las técnicas de solución de conflictos alternativos al procedimiento jurisdiccional, en evidente función deflacionaria del contencioso jurisdiccional: entre estas, además de la posibilidad de transferir a sede arbitral los procedimientos pendientes ante la autoridad judicial ${ }^{112}$, viene obviamente la "mediación conciliatoria", ya no a modo experimental (por lo tanto "a tiempo"), sino de manera estable y permanente ${ }^{113}$.

Y bien: si son analizados los datos de la "mediación conciliatoria" del 2017, se entiende que con que los números en relación al contencioso son realmente pequeños: en el inicio del año había pendientes 85.499 procedimientos, en el año fueron inscritos 166.989, fueron definidos 155.457 y al final del año resultaron pendientes $97.031^{114}$.

Ciertamente, algunas intervenciones correctivas pueden imaginarse: sea en derecho vigente o sea de jure condendo.

\footnotetext{
${ }^{104}$ Ministerio de Justicia.

105 Según la L. n 89/2001 (llamada legge Pinto).

${ }^{106}$ Ministerio de Justicia.

107 Informe sobre ciudadanos y justicia civil (Instituto nacional de estadísticas de Italia, 2015).

108 Ver, respectivamente, el Art. 348-bis c.p.c., introducido por el D.L. $n^{\circ}$ 83/2012; y el Art. 360-bis c.p.c., introducido por el L. $n^{\circ} 69 / 2009$.

109 En el orden, Art. 96, segundo y tercer párrafos, c.p.c.

${ }_{110}$ Al menos cuando se deposita en modo telemático: Art. 16 bis L. $n^{\circ}$ 221/2013, modificado por el L. n. $132 / 2015$.

${ }^{111}$ En el orden, Art. 132, segundo párrafo, n 4, c.p.c. y el Art. 118, primer párrafo, disp. att. y trans. c.p.c., según enmendado por L. n $69 / 2009$.

112 Art. 1 D.L. $n^{\circ} 132 / 2014$.

${ }^{113}$ Art. 11 ter, primer párrafo, D.L. n 50/2017

114 Ministerio de Justicia.
} 


\section{Maurizio Onza}

Y así, para proponer algún ejemplo, en cuanto a derecho vigente, la jurisprudencia puede actuar por la vía de interpretar las disposiciones sobre incentivos y desincentivos. En particular: considerando la no participación en el procedimiento de mediación, sin causa justificada, como una fuente de prueba suficiente y única para la decisión del juez; sancionando la conducta no colaborativa, que ha determinado el fallo de la "mediación conciliatoria", con la condena, en caso de derrota, incluso al pago, a título de mayor daño, de las costas extrajudiciales generadas en el procedimiento conciliativo ${ }^{115}$; aplicando las consecuencias derivadas de la falta de participación sin motivo justificado, independientemente del resultado ${ }^{116}$ (Art. 88 c.p.c.); considerando la participación en el procedimiento de "mediación conciliatoria" como expresión del deber de lealtad de las partes ${ }^{117}$, textualmente previsto para los procedimientos jurisdiccionales ${ }^{118}$, susceptible entonces de valoración para los fines de la decisión y de la atribucion de las costas procesales; estimando la participacion en el procedimiento como una "conducta absolutamente necesaria", que las partes no pueden omitir, si no es en presencia de un motivo impeditivo justificado que tenga caracteres de absoluto ${ }^{119}$; exigiendo que la participación en el procedimiento sea "efectiva" y que, por lo tanto, que las partes no se limiten a la sola sesión informativa, debiendo además estar presentes personalmente ${ }^{120}$.

De jure condendo, se podrían recibir algunas posiciones jurisprudenciales ${ }^{121}$ y colmar la incerteza de la disciplina vigente. Entre las varias, por ejemplo y respecto al primer perfil, obligando a una efectiva y personal participación de las partes al procedimiento; y, respecto al segundo, identificar a quienes incurren en la carga de iniciar una "mediación conciliatoria" en caso de oposición al decreto preceptivo, una vez que la ejecución provisional ha sido otorgada o suspendida ${ }^{122}$.

Entre otros. No todos son conscientes de la posibilidad de alcanzar un acuerdo recíprocamente satisfactorio a través de formas de resolución no "jurisdiccional": en una investigación del $2015^{123}$, solo el $43,9 \%$ de los entrevistados conocía el significado de "mediación civil". E incluso está expresamente previsto que el abogado deba informar al cliente, al momento de conferirse el encargo y a pena de anulación del contrato de actuación profesional, de la posibilidad de valerse de la "mediación conciliatoria" y de los beneficios fiscales ${ }^{124}$ a que se refieren los artículos 17 y 20.

Y entonces, tal vez, el verdadero problema es aquel de crear una cultura conciliativa: sea entre las partes en conflicto, sea en los abogados que deben considerar la "mediación conciliativa" como una oportunidad de formar una nueva profesión como mediador y de asistencia del cliente en la mediación ${ }^{125}$.

No parece fácil de entender si para formar una "cultura" conciliativa pueda ser útil o no la apmpliación de las materias sujetas a la condición de procedencia

115 Corte de Milán, 21 de julio de 2016.

${ }_{116}$ Corte de Mantua, 14 de junio de 2016.

117 Art. 88 c.p.c.

118 Corte de Roma, $n^{\circ}$ 22475/2017.

${ }^{119}$ Corte de Vasto, 16 de diciembre de 2016.

${ }^{120}$ Corte de Roma, 14 de junio de 2016.

${ }^{121}$ En este sentido se mueven las propuestas de la Comisión de estudio para la elaboración de hipótesis de disciplina orgánica y de reforma de los instrumentos de desjuridicción, en especial respecto de la mediación, la negociación asistida y el arbitraje, del Ministerio de justicia de Italia (Proposte normative e note illustrative, 2017).

${ }^{122}$ En la doctrina, ver Califano (2017) En la jurisprudencia, confrontar Cass. No 24629/2015. En el mismo sentido, para la aplicación o no de la "mediación de conciliación" a las terceras partes puestas en entredicho, sobre las cuales, por ejemplo, ver Corte de Palermo, 27 de febrero de 2016.

${ }^{123}$ Informe sobre ciudadanos y justicia civil (Instituto nacional de estadísticas de Italia, 2015).

${ }^{124}$ Art. 4, tercer párrafo, D.Lgs. $n^{\circ}$ 28/2010.

${ }^{125}$ Comisión de estudio, (2017), p. 16. 


\section{La mediación conciliatoria de los conflictos civiles y comerciales en Italia}

de la "mediación conciliatoria"; ampliación que, de jure condendo, ha sido por cierto propuesta ${ }^{126}$. Sin embargo, es correcto que para formar "cultura" es necesario invertir recursos y no solo introducir nuevas reglas en el ordenamiento jurídico o perfeccionar y corregir aquellas existentes. Esto, tal vez, debería entender el legislador italiano.

\section{Referencias}

Califano, G. P. (2017). Su due attuali problemi in materia di mediazione obbligatoria: in relazione agli interventi di terzi e al procedimento monitorio; tra ciò che mi piacerebbe e ciò che invece mi appare. Giustizia Civile: revista giuridica trimestrale (4), 999-1010.

Ceolin M. (2018). Procedimento di mediazione ex d. legis. n. 28/2010 ed ipoteca giudiziale: nessuna deroga ai principi generali: Nota a Trib. Ascoli Piceno 11 ottobre 2017. La Nuova Giurisprudenza Civile Commentata (3), 324-330.

De Mauro, T. (2000). Conciliazione. In Grande Dizionario dell'uso. Torino: Utet.

Ferraris, F. (2016). Mediazione civile e commerciale. In Enciclopedia del diritto - Annali. Milano: Giuffrè.

Grossi P. (2017). La invenzione del diritto: a proposito della funzione dei giudici. Rivista trimestrale di diritto e procedura civile 71 (3), 831-846.

Instituto nacional de estadísticas de Italia, Informe sobre ciudadanos y justicia civil (2015). Recuperado de https:// www.istat.it/it/files//2016/09/Cittadini-e-giustizia-civile-23_09_2016PC.pdf (Fecha de consulta 16 de abril de 2018).

Irti N. (2014). La Crisi della fattispecie. Rivista di diritto processuale 69 (1), 36-44.

Irti N. (2016). Un diritto incalcolabile. Torino: Giappichelli Editore.

Lipari N. (2018). II diritto civile dalle fonti ai principi. Rivista trimestrale di diritto e procedura civile 72(1), 5-37.

Lucchini Guastalla, E. (2015). Arbitro Bancario finanziario. In Enciclopedia del diritto, Annali 8 (p. 35). Milano: Giuffré.

Marzocco, A. M. (2012). Requisiti di forma-contenuto ed effetti dell'istanza di mediazione. Rassegna di diritto civile (4), 1127-1163.

Marzocco, A. M. (2012). Le controversie in materia di comunicazioni elettroniche: contributo allo studio della giurisdizione condizionata. ROMA: Dike Giuridica Editrice.

Ministerio de Justicia, Comisión de estudio, Proposte normative e note illustrative, Recuperado de https://www.mfsd. it/sys_dati_open.php?open_UID=PDF_9009DDC304839DB3\&open_source=module_upload_contents_files (Fecha de consulta 16 de abril de 2018).

Simone Alvaro (Coord.) (2018). Tutela degli investitori e dei clienti degli intermediari e ADRs. Atti del convegno Consob. Milano, Università Bocconi: Quaderni giuridici Co.n.so.b.

\footnotetext{
${ }^{126}$ Extender la condición de procesabilidad a conflictos relacionados con otras relaciones de duración (contratos de obra, trabajo profesional, compras privadas, franquicias, arrendamiento, suministro y administración) y relaciones sociales relacionadas con las empresas de personas. Se ha dicho que las partes en conflicto están persiguiendo un propósito común y tienen interés en resolverlo "mediante un método que favorezca la definición amistosa, asegurando la confidencialidad y flexibilidad de las soluciones" (Comisión de estudio, 2017, p. 37). Además, la propia Comisión constató que la disposición de organismos específicamente dedicados a la solución de conflictos parece que da mejores resultados. Por ejemplo, el CORECOM para el conflicto en las comunicaciones, los procedimientos promovidos por la autoridad para la energía y el gas, y especialmente para el ABF (Comisión de estudio, 2017, p. 16).
} 